\title{
Nuevas perspectivas de la historia oaxaqueña
}

\section{Francie Chassen y su mirada desde el sur}

\author{
Laura Machuca
}

FRANCIE R. CHASSEN-LÓPEZ, 2004

From Liberal to Revolutionary Oaxaca. The View from the South. Mexico 1867-1911

The Pennsylvania University Press, Pennsylvania, 608 pp.

S in ninguna duda el libro From Liberal to Revolutionary Oaxaca de Francie Chassen-López resulta de gran trascendencia, no sólo para la historiografía de Oaxaca, sino para la del siglo XIX mexicano en general. Chassen es profesora de historia en la Universidad de Kentucky y en la actualidad funge como directora del Programa de Estudios Latinoamericanos. Con esta obra ganó el premio al mejor libro publicado en 2004 del Rocky Mountain Council for Latin American
Studies' Thomas McGann. Fruto de varios años de investigación y de los entrañables lazos que la unen con esta tierra, el trabajo resulta en una historia global del estado de Oaxaca en los decisivos años de 1867 a 1911.

El título "La vista desde el sur" — prestado de un artículo de William Taylor - resulta para ella una herramienta metodológica, pues la mirada focalizada en el sur le permite examinar, en una región acotada, los procesos que se llevaban a cabo en el país

\section{New Perspectives of Oaxaca's History. Francie Chassen and Her View from the South}

LAURA MACHUCA: Centro de Investigaciones y Estudios Superiores en Antropología Social-Peninsular, Mérida, México.

$<$ laurama@ciesas.edu.mx>

Desacatos, núm. 28, septiembre-diciembre 2008, pp. 191-195.

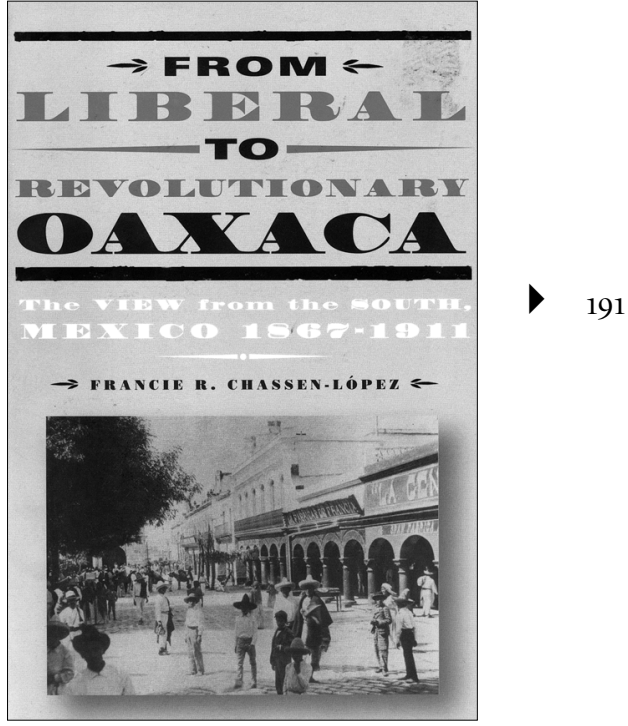

para desentrañar sus cambios y sus límites, así como mostrar una imagen independiente del centro.

Chassen se inspira en los "Subaltern Studies" — corriente histórica desarrollada en India a partir de fines de la década de 1970, con el propósito de reconocer la centralidad y la capacidad (agency) de los grupos subordinados que habían sido olvidados por las élites en la construcción 
histórical ${ }^{1}$, muy en particular en los textos de Ranahit Guha y Gyan Prakash —este último sugiere una "lectura insurgente" de los textos históricos-. Como es fácil adivinar, para el caso oaxaqueño los grupos subalternos son los indígenas de las dieciséis etnias del estado, que ella observa en persistente lucha y negociación, participando en la formación del Estado, incluyendo además a las mujeres y los grupos de clases medias y bajas.

Otro concepto fundamental que introduce, además de agency, es el de etnicidad, pues para ella resulta importante discernir los modelos que marcan la diferenciación entre clase, género e identidad étnica para distinguir las cambiantes relaciones de poder $\mathrm{y}$ entender los mecanismos de cambio y continuidad. Así, entiende por etnicidad "un proceso histórico de muchas caras, en el cual las identidades étnicas y los grupos étnicos están constituidos dinámicamente en la práctica social" (p. 292), que además cambia y se adapta de acuerdo con las circunstancias históricas. Se construye en conflicto con el otro; por lo tanto, las etnicidades indígenas se definen por lo que reconocen como cultura prehispánica, las tradiciones y costumbres salvaguardadas frente al colonialismo español. El mejor ejemplo de adaptación serían los chatinos, que aprendieron a sortear todas las presiones venidas de fuera.

\footnotetext{
${ }^{1}$ Sobre esta corriente véanse los libros de Saurabh Dube, Pasados poscoloniales. Colección de ensayos sobre la nueva historia y etnografía de la India, Germán Franco Toriz (trad.), El Colegio de México, México, 1999, y Sujetos subalternos, Germán Franco y Ari Bartra (trads.), El Colegio de México, México, 2001.
}

El libro se divide en tres partes que buscan contestar tres preguntas: ¿juárez y Díaz descuidaron su estado en aras de la modernización? ¿Los indígenas fueron un obstáculo para el progreso? ¿Oaxaca permaneció al margen del movimiento revolucionario?

En la primera parte, "Infraestructura y economía", la autora analiza la base material que daba sustento al estado: la tierra, sus productos, el comercio, la industria y la minería. En primer lugar se refiere a la entrada del ferrocarril y las expectativas que abrió en cuanto a que representaba el inicio de una nueva era de prosperidad y modernización para Oaxaca. Tuvieron preferencia las vías con salidas al exterior (como Salina Cruz o Puerto México), que sirvieron para activar el comercio internacional. En cambio, las líneas Istmo-Oaxaca y Mixteca-Puebla nunca vieron la luz, por lo tanto, no se logró la articulación económica del estado.

Después, Chassen analiza el tema de la tierra y parte de la idea de que ésta entró a la modernización durante el Porfiriato, pero el proceso no fue homogéneo, fueron más afectadas las regiones donde llegó el ferrocarril. Los pueblos indios no permanecieron indiferentes y buscaron todas las vías posibles para perder menos tierras; algunos lograron retenerlas, sobre todo aquéllos de regiones aisladas alejadas de la agricultura capitalista. Dos procesos sucedieron en aras del "progreso": el primero fue la conversión de varios indígenas en propietarios individuales -lo que dio nacimiento a minifundios-, y el segundo, la venta de ejidos $y$ tierras comunales a empresas dedicadas a la agricultura comercial.
Otra característica importante del periodo es que tampoco la hacienda logró imponerse; el porcentaje de las tierras ocupadas por éstas era muy bajo. Sin embargo, durante el Porfiriato surgió, en las regiones donde se impuso el desarrollo, una propiedad híbrida: la finca (también conocida como plantación, cafetal, ingenio o trapiche, dependiendo de su ubicación y producción). Chassen utiliza el término de finca para distinguirla de los minifundios, de las haciendas y de las propiedades rurales en general no surgidas durante el Porfiriato, y la define como "una empresa agraria dedicada al cultivo comercial, agricultura o ganado, integrado dentro del mercado nacional o internacional durante el Porfiriato" (p. 118), situada en las tierras que habían sido comunales y en las regiones en desarrollo: Papaloapan, Istmo, Cañada y Costa, donde coincidentemente también hubo un aumento considerable de ranchos (medianos propietarios que aprovecharon la especulación de tierras), lo cual hace sugerir a la autora una relación entre éstos y la actividad revolucionaria.

En seguida, Chassen se enfoca en el proceso de desarrollo porfirista a nivel local, nacional e internacional: por una parte, examina cada uno de los productos que demandaban los mercados (café, tabaco, hule, plátanos, caña de azúcar, algodón y, en menor medida, cacao, algodón, arroz y añil); por la otra, analiza las diferentes maneras empleadas para proveerse de mano de obra. La autora distingue cuatro factores que caracterizaron las relaciones de trabajo en vísperas de la Revolución: a) la supervivencia 
de los comuneros; b) la baja formación de la fuerza de trabajo que sólo dependía de su salario, que por cierto era uno de los más bajos de todo México; c) la existencia de un esclavismo informal en Tuxtepec, y d) el uso limitado del peón acasillado (p. 178). En zonas como Juquila (Costa) se ha documentado asimismo "el enganche" o trabajo forzado. Para Chassen, estas situaciones de esclavismo o enganche eran producto de las fuerzas nacionales y locales, y si bien no estaban determinadas por el capitalismo global, sí obedecían a la presión exterior.

El último capítulo de la primera parte está dedicado a la minería, a la industria y al comercio. Como la autora lo muestra, el auge de la minería está muy ligado también a la introducción del ferrocarril, pues el gobierno creía que ambos traerían prosperidad al estado, razón por la cual trataron de atraer capitales y tecnología. Sin embargo, fue un despertar efímero debido a la crisis mundial del metal en 1907, que desplomó los precios. La industria ni siquiera logró despegar, pues los pueblos seguían teniendo una producción artesanal que satisfacía las necesidades y, aunque el comercio era un rubro importante, no se manejaban los mismos capitales que en Yucatán con el henequén, o en Morelos, con el azúcar, entre otros casos.

En la segunda parte, "Sociedad: clase, etnicidad y género", la autora se centra en la población indígena y las relaciones que establecieron con los "otros". Durante el periodo estudiado, Oaxaca y sus poblaciones conocieron un aumento demográfico. Además, se observa la aparición de nuevas clases y

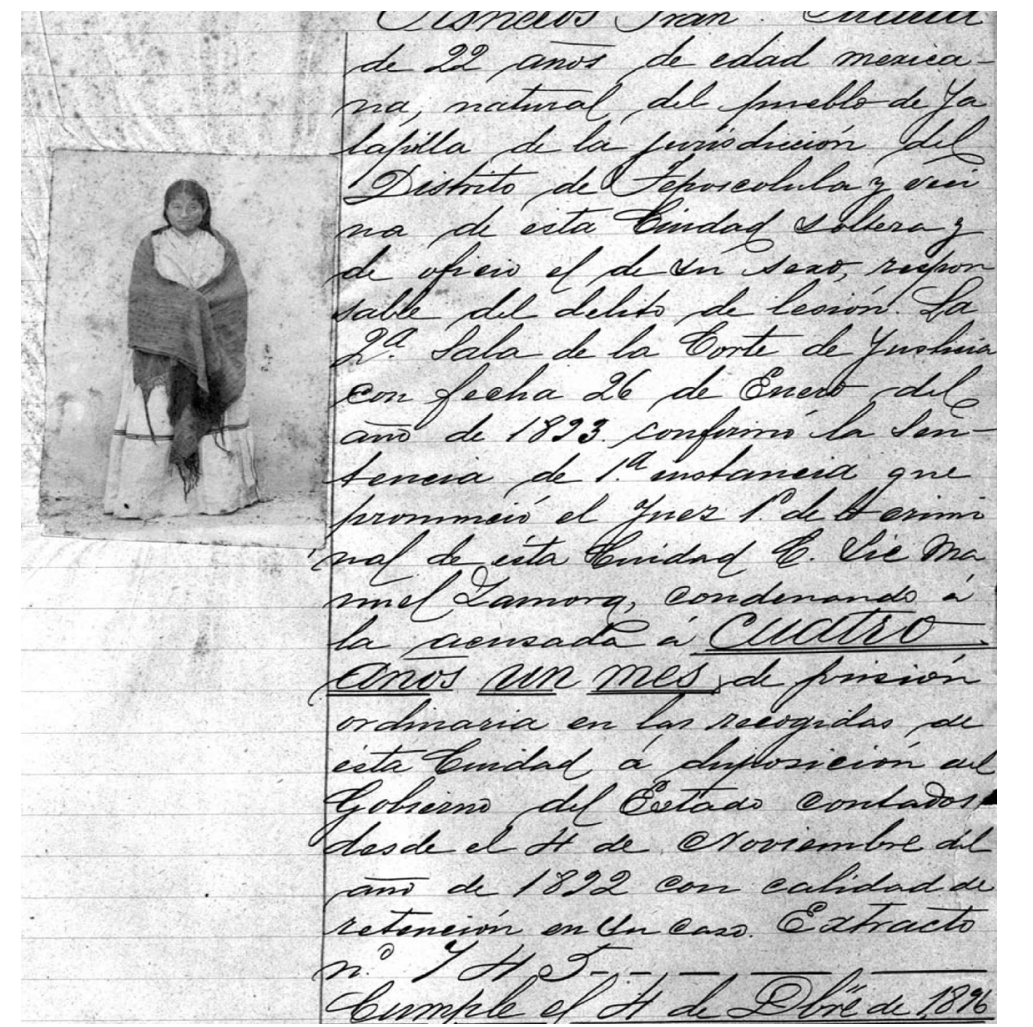

Francisca María Cisneros, en F. J. Ruiz Cervantes y C. Sánchez Silva (coords.), De oficios y otros menesteres. Imágenes de la vida cotidiana en la ciudad de Oaxaca, UABJO, INAOE, Oaxaca, 2005.

la redefinición de las que ya existían. Las élites se reconfiguran y aceptan (como en la época colonial) a los inmigrantes, que siguen siendo en su mayoría españoles, pero también hay ingleses, franceses, italianos, estadounidenses y alemanes. Su apertura alcanzó asimismo a los militares y a los nuevos políticos, ambos de cunas humildes. Para Chassen esta situación fue fruto de la reforma liberal, pues permitió la compra y acumulación de tierras, siendo el mejor ejemplo de esta movilidad social el mismo Porfirio Díaz. La clase media se expande en la ciudad, así como los rancheros y pe- queños propietarios en el campo. La clase trabajadora aumenta en la industria minera, portuaria, fabril y de ferrocarriles.

Chassen introduce a las mujeres en su análisis y observa que su presencia se acrecienta en las actividades económicas y productivas: en su mayoría trabajaban en las fábricas y en el campo, pero algunas también estudiaron para maestras y médicas. Asimismo, el número de propietarias urbanas y rurales (poseedoras de haciendas) creció, en parte por haberles favorecido las leyes de desamortización para la compra de casas y tierras. 


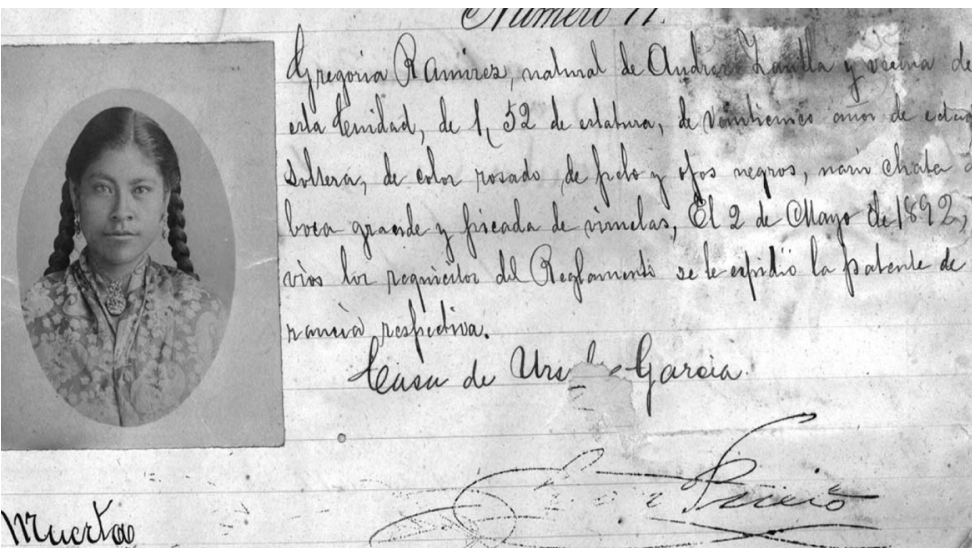

Gregoria Ramírez, en F. J. Ruiz Cervantes y C. Sánchez Silva, op. cit.

La élite del Valle de Oaxaca - la vallistocracia - dominaba a las oligarquías de las otras regiones, salvo las istmeñas, que siempre fueron más independientes. Chassen distingue dos grupos en la clase media: por un lado, todo por doctores, abogados y jefes políticos, varios formados en el importante Instituto de Ciencias y Artes, todos clientela de la vallistocracia; por el otro, la clase media baja, compuesta de maestros, licenciados, pequeños propietarios, comerciantes, capataces y rancheros. De este grupo salieron los más radicales opositores políticos. También se ocupa de otros grupos, como los artesanos, obreros, bandidos, prostitutas y pordioseros.

Una parte fundamental de su análisis lo ocupan las luchas sociales que los indígenas entablaron para hacer respetar sus tierras contra la embestida liberal y para frenar las leyes que iban en contra de sus derechos. Para Chassen, la comunidad, que significa la "representación de las relaciones recíprocas entre los miembros, es un pro- ceso dinámico. No importa si ellos eran zapotecos, mixtecos, huaves o mazatecos, es una unidad social y territorial, el común del pueblo, que proveía a la gente con un sentido propio de la identidad, la labor y el derecho" (p. 291). La autora plantea que los pueblos pugnaban, resistían, negociaban, y que sus costumbres "inmemoriales" iban cambiando con el paso del tiempo.

Chassen observa que los movimientos sociales no podían extenderse más allá de las fronteras de un municipio pues, aunque no cita en esta parte a Luis González, ya se sabe que los habitantes se sienten más identificados con gente de su pueblo que con otros de su misma etnia. La excepción fue el Istmo, donde sí se logró la unión de varias etnias en las guerras del siglo XIX, lo que representó la emergencia de una identidad multiétnica.

Dos fueron los principales ataques contra los pueblos: la capitación subió al doble y se aplicaron las leyes de desamortización. Chassen critica, en particular, la visión de Carmagnani de una segunda conquista en el siglo XIX, y la de Carlos Sánchez Silva, de considerar esos años como los de un largo proceso de estancamiento de las élites $^{2}$. Los pueblos indios no estaban sentados llorando su suerte; al contrario, integraban a sus usos y costumbres las nuevas fuerzas económicas y sabían desplegar estrategias para defender sus derechos a nivel local, regional, estatal y nacional. En ese sentido cita dos ejemplos importantes: la lucha del pueblo de Santa María Yucuiti contra la familia Esperón, y los movimientos en el istmo de Tehuantepec.

Los pueblos indios desarrollaron sus formas cotidianas de resistencia. En caso de asuntos más graves empezaban negociando, primero informalmente, después con protestas pacíficas; si lo anterior no funcionaba, entonces entablaban un proceso judicial. Cuando la situación llegaba a un punto insostenible surgía la violencia. Chassen identifica tres grandes rebeliones en el periodo estudiado: las del Istmo, las de la Mixteca ligadas al movimiento de Guerrero y la de los impuestos, mejor conocida como "la Guerra de los Pantalones"3. Los indígenas demandaron

\footnotetext{
${ }^{2}$ Marcello Carmagnani, El regreso de los dioses. El proceso de reconstitución de la identidad étnica en Oaxaca. Siglos XVII y XVIII, Fondo de Cultura Económica, México, 1988, y Carlos Sánchez Silva, Indios, comerciantes y burocracia en la Oaxaca poscolonial, 1786-1860, Instituto Oaxaqueño de las Culturas, Fondo Estatal para la Cultura y las Artes, Universidad Autónoma Benito Juárez de Oaxaca (UABJO), México, 1998, pp. 56-57, 185-187.

3 "La Guerra de los Pantalones", desatada por el aumento de la capitación y por una ley que decretaba que todos debían vestir al estilo europeo, es decir, llevar pantalones. Especialmente los chatinos fueron los más aguerridos y se negaron de manera determinante a cambiar su vestido tradicional.
} 
ser reconocidos como ciudadanos y gozar de tal estatus, pero su idea era la de una ciudadanía colectiva, cuya soberanía residía en el mismo pueblo.

En la tercera parte, "Cultura política y revolución", se estudian los personajes y las principales características del movimiento revolucionario en sus vísperas. No podía dejar de hablar de Juárez y Díaz, pero más que diferencias Chassen encuentra continuidad y similitud entre los dos: sus metas, su idea de nación, sus trayectorias e incluso sus orígenes. Los dos fueron ambivalentes en cuanto a su posición respecto a los pueblos indios campesinos, algunas veces defendiéndolos, otras atacándolos. Según la autora, sin duda durante el gobierno de Emilio Pimentel hubo un mejoramiento de la economía (que no acabó sino hasta la crisis de 1907) y de la educación, de la ciencia y de las artes, pero estas mejoras sólo favorecieron a las élites. El gran número de publicaciones, aunque de aparición efímera, contrastaba con el alto nivel de analfabetismo.

Los caciques siguieron como intermediarios políticos, económicos y culturales. Sobre todo resalta la importancia de los caciques de la Sierra Norte y de algunas mujeres, como sería el caso de Juana Catarina Romero, de Tehuantepec, a cuyo estudio Chassen ha dedicado también varios años. Oaxaca era un estado políticamente fragmentado y la autora opina que al gobierno de Díaz simplemente le faltó la capacidad de centralizar todo el poder, porque los pueblos indios gozaban de cierta autonomía que defendían (p. 445).

Otros personajes sobresalientes durante este periodo fueron, por un lado,

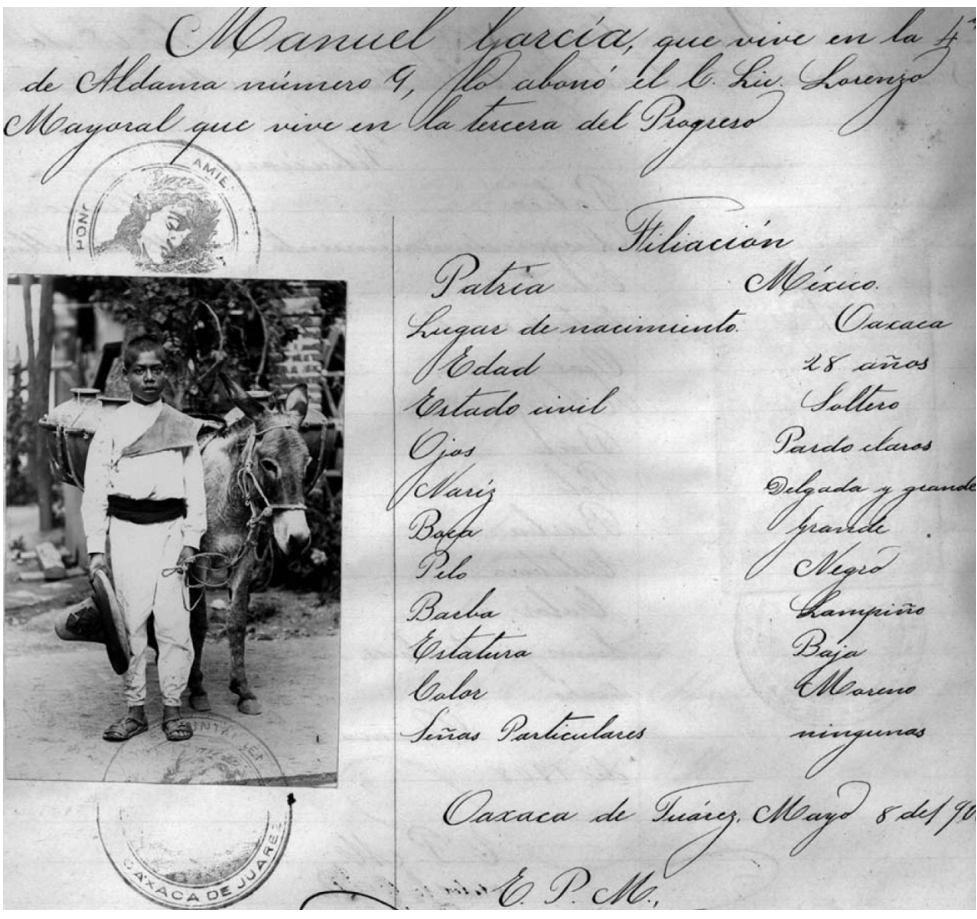

Manuel García, en F. J. Ruiz Cervantes y C. Sánchez Silva, op. cit.

los luchadores sociales, por lo cual no podía faltar Ricardo Flores Magón - también oaxaqueño-y el establecimiento del Partido Liberal Mexicano en Oaxaca; por el otro, Benito Juárez Maza y su ascenso político. El juarismo triunfó sobre el porfirismo, pero el primero emergió como una nueva limitación para la política revolucionaria en Oaxaca, que se mantenía bajo el peso de un doble legado.

Chassen concluye que la ciudadanía y la identidad, lejos de ser una comunidad imaginada por las élites, fue refutada y construida desde abajo por las clases sociales populares y las etnias de los pueblos y ciudades de toda la nación. Los pueblos indios no eran ni tradicionales ni modernos: "tradujeron nuevas ideas y factores a sus vidas por medio de una negociación de la modernidad, más que articular o defender modernidades alternativas. La emergencia de esta creatividad híbrida —cultural, económica y política- nos permite ir más allá de la resistencia”.

El libro de Francie Chassen no sólo viene a llenar un hueco historiográfico — pues el periodo que comprende su estudio había sido un poco olvidado- - sino que ofrece una visión muy novedosa que abre nuevas líneas de investigación y sugiere preguntas diferentes para abordar la segunda mitad del siglo XIX oaxaqueño. La lectura de sus 600 páginas es muy recomendable, así como su traducción al español, para que el público interesado en temas oaxaqueños pueda conocerlo.

Agosto 2007 